\title{
26414 - DESFLURANE CAUSES MORE ATRIAL FIBRILLATION AND TACHYCARDIA AFTER OFF-PUMP AORTO-CORONARY BYPASS GRAFTING (OPCAB) THAN SEVOFLURANE
}

\section{Thomas Hemmerling MD, Ignatio Prieto, MD; Fadi Basile, MD; Nicolas Noiseux, University Of Montreal, Montreal, PQ, Canada}

INTRODUCTION. All volatile anesthetics provide protection against myocardial ischemia by pharmacologic preconditioning. Desflurane and sevoflurane seem ideal to fast-track patients after cardiac surgery. This study compares their arrythmogenic potential in patients after off-pump cardiac surgery (OPCAB).

METHODS. Forty patients undergoing OPCAB with TEA and ultra-fast-track anesthesia were randomized in this pilot study in two groups of 20 patients. Anesthesia was maintained with either 1 MAC of sevoflurane or 1 MAC of desflurane. Continuous ECGmonitoring for the detection of arrhythmias was performed during and up to $72 \mathrm{~h}$ after surgery, Troponine-T, CK-MB, regional wall motion abnormalities and ejection fraction, time to extubation, respiratory functions and hemodynamic stability were compared using t-test or Chi-square test. $\mathrm{P}<0.05$.

RESULTS. All patients were successfully extubated in the operating room with minimal post-operative pain up to $72 \mathrm{~h}$ after surgery. Troponine-T and CK-MB levels, immediately after surgery, 3, 12, 24, 48 and 72h after surgery, were not statistically different between the two volatile agents. Hemodynamic stability during surgery and preservation of ejection fraction were equally not different between the two groups. Time to extubation was equally short with sevoflurane at $12 \mathrm{~min}$ (4) and desflurane at $11 \mathrm{~min}$ (5). There were significantly more patients with atrial fibrillation and tachycardia in the desflurane group than in the sevoflurane group. Before being discharged from the hospital, the atrial fibrillation was converted either spontaneously or pharmacologically or by electro conversion to sinus rhythm. In addition, 6 patients in the desflurane group against 1 patient in the sevoflurane group showed an agitated state immediately after surgery which settled spontaneously within $2 \mathrm{~h}$.

DISCUSSION. Our pilot study shows that desflurane causes more arrythmias than sevoflurane after OPCAB. The findings of our prospective study are consistent with a recent retrospective analysis of patients after on-pump cardiac surgery. (1) They do not differ in providing hemodynamic stability or myocardial protection during or after aortocoronary grafts. Recovery from anesthesia was equally fast after both volatile anesthetics as was respiratory function. Sevoflurane is superior to desflurane for anesthesia for OPCAB since it provides significantly less atrial fibrillation and supraventricular tachycardia whilst providing equally fast extubation times.

1 Acta Anaesthesiol Belg. 2005;56(2):147-54. 


$\begin{array}{lcc} & \begin{array}{c}\text { Sevoflurane } \\ (\mathbf{N}=\mathbf{2 0})\end{array} & \begin{array}{c}\text { Desflurane } \\ \mathbf{N}=\mathbf{2 0})\end{array} \\ \text { Atrial fibrillation } & \mathbf{1} & \mathbf{5}^{*} \\ \text { Atrial flutter } & 0 & 0 \\ \text { Supraven tricular Tachycardia } & 0 & \mathbf{5}^{*} \\ \text { Ventricular tachycardi a or fibrillation } & 0 & 0 \\ \text { Bradycardia } & 4 & 3 \\ \text { "Values are presented as actual number of patints } & & \end{array}$

